\title{
Papers
}

\section{Legislation for smoke-free workplaces and health of bar workers in Ireland: before and after study}

Shane Allwright, Gillian Paul, Birgit Greiner, Bernie J Mullally, Lisa Pursell, Alan Kelly, Brendan Bonner, Maureen D’Eath, Bill McConnell, James P McLaughlin, Diarmuid O’Donovan, Eamon O'Kane, Ivan J Perry

\begin{abstract}
Objectives To compare exposure to secondhand smoke and respiratory health in bar staff in the Republic of Ireland and Northern Ireland before and after the introduction of legislation for smoke-free workplaces in the Republic. Design Comparisons before and after the legislation in intervention and control regions.

Setting Public houses in three areas in the Republic (intervention) and one area in Northern Ireland (control). Participants 329 bar staff enrolled in baseline survey; 249 $(76 \%)$ followed up one year later. Of these, 158 were non-smokers both at baseline and follow-up.

Main outcome measures Salivary cotinine concentration, self reported exposure to secondhand smoke, and respiratory and sensory irritation symptoms.
\end{abstract}

Results In bar staff in the Republic who did not themselves smoke, salivary cotinine concentrations dropped by $80 \%$ after the smoke-free law (from median $29.0 \mathrm{nmol} / \mathrm{l}$ (95\% confidence interval 18.2 to $43.2 \mathrm{nmol} / \mathrm{l}))$ to $5.1 \mathrm{nmol} / \mathrm{l}(2.8$ to $13.1 \mathrm{nmol} / \mathrm{l})$ in contrast with a $20 \%$ decline in Northern Ireland over the same period (from median $25.3 \mathrm{nmol} / \mathrm{l}$ (10.4 to $59.2 \mathrm{nmol} / \mathrm{l})$ to $20.4 \mathrm{nmol} / \mathrm{l}(13.2$ to $33.8 \mathrm{nmol} / \mathrm{l}))$. Changes in self reported exposure to secondhand smoke were consistent with the changes in cotinine concentrations. Reporting any respiratory symptom declined significantly in the Republic (down 16.7\%, $-26.1 \%$ to $-7.3 \%$ ) but not in Northern Ireland ( $0 \%$ difference, $-32.7 \%$ to $32.7 \%$ ). After adjustment for confounding, respiratory symptoms declined significantly more in the Republic than in Northern Ireland and the decline in cotinine concentration was twice as great.

Conclusion The smoke-free law in the Republic of Ireland protects non-smoking bar workers from exposure to secondhand smoke.

\section{Introduction}

In response to the evidence on the adverse effects of passive smoking on health, ${ }^{1-3}$ on 29 March 2004 the Republic of Ireland introduced a comprehensive smoke-free law, covering all indoor workplaces, including bars and restaurants..$^{4-6}$ Introduction of this legislation in the Republic but not in neighbouring Northern Ireland, with its comparable population, environment, and culture, was a form of "policy randomisation,"” creating a natural experiment for identifying effects of the new law.

To date few studies have investigated whether legislation for smoke-free workplaces protects the health of workers. Cross sectional surveys before and after similar legislation in Finland in
1995 showed a decline in self reported exposure to secondhand smoke in workers from several non-hospitality workplace settings. ${ }^{8}$ Some of the highest and most sustained occupational exposures to secondhand smoke occur in bar staff, ${ }^{10}$ with nonsmoking areas providing only limited protection. ${ }^{11}$ Carbon monoxide concentrations in pubs in Galway indicated high exposure in Irish bar workers. ${ }^{12}$ Eisner and colleagues examined 53 bar staff in San Francisco one month either side of the 1998 statewide law in California banning smoking in bars. ${ }^{13}$ They concluded that the law was associated with a rapid improvement in respiratory health.

We examined the impact on bar staff of a national workplace smoke-free law by using laboratory assessment of exposure to secondhand smoke and by controlling for unrelated secular trends. We compared exposure to secondhand smoke and respiratory health in bar staff in rural and urban areas of the Republic of Ireland before and after the law and compared these changes with changes observed in Northern Ireland.

\section{Methods}

We enrolled staff working in pubs in the Republic and Northern Ireland in a baseline survey in the six months leading up to the ban (September 2003 to March 2004) and followed them up one year later (September 2004 to March 2005) to assess changes in exposure to secondhand smoke and symptoms (natural experiment).

\section{Sample selection}

Three areas in the Republic (Dublin, Cork, and County Galway) were selected to represent different types of pub environment, together with one area in the north west of Northern Ireland. Sampling procedures were adapted to local circumstances to maximise follow-up. In Dublin, we selected city centre and suburban pubs. The main trade union for Dublin bar workers (Mandate) forwarded our letter asking members to contact the research team if they were interested in participating. All pubs on randomly selected streets in Cork city were invited to participate and up to two bar staff were randomly selected from each pub. In Galway, we identified rural and family owned pubs by selecting electoral districts with populations of less than 1500. In Northern Ireland, we selected pubs from Derry City Council area and the adjoining rural Strabane and Limavady Council areas. All staff present in the Galway and Northern Ireland pubs on the day of the survey were asked to participate.

Although we enrolled both smokers and non-smokers, this analysis is restricted to participants who were non-smokers at both baseline and follow-up. 


\section{Conduct of survey}

We invited Dublin bar staff to a hospital respiratory laboratory for salivary cotinine testing and administration of the questionnaire. Bar staff from the three other areas and the few Dublin staff who did not wish to attend the laboratory were interviewed in their workplace (pub). Most follow-up interviews were conducted in the same month as the baseline survey; at least two attempts at contact were made. GP trained all the interviewers.

\section{Exposure to secondhand smoke}

Salivary cotinine-Non-stimulated saliva samples (about $1 \mathrm{ml}$ ) were collected according to the protocol used in the Health Survey for England. ${ }^{14}$ Samples were frozen and sent in batches to ABS Laboratories, London, who performed cotinine assays blind with a rapid gas-liquid chromatographic method suitable for use in non-smokers. ${ }^{15}$ We ascertained smoking status because active smoking is the main influence on cotinine concentrations. As cotinine half life is about 20 hours, ${ }^{16}$ length of time since last working also impacts on cotinine concentrations. This was therefore recorded for the Dublin participants. Participants interviewed in pubs were asked what time they started the current shift. The number of hours worked in the past two days was recorded for all participants.

Self reported exposure-We recorded hours of exposure to secondhand smoke at work and in total (including work, home, and other regular activities) over the past seven days and whether participants lived with a smoker.

Respiratory and sensory symptoms-We used questions developed by Eisner, Smith, and Blanc to get information on symptoms of respiratory and sensory irritation. Respiratory questions were adapted from the validated bronchial symptoms questionnaire of the International Union against Tuberculosis and Lung Disease. ${ }^{13}$

\section{Statistical analysis}

A nationally representative survey of the US population used $85.2 \mathrm{nmol} / \mathrm{l}(15 \mathrm{ng} / \mathrm{ml})$ serum cotinine as a cut off for distinguishing smokers from non-smokers. ${ }^{17}$ Heavy exposure to secondhand smoke, however, may produce saliva concentrations as high as $177.8 \mathrm{nmol} / \mathrm{l}(31.3 \mathrm{ng} / \mathrm{ml}) .{ }^{10}$ Given the high exposures in bar workers, ${ }^{9}{ }^{10}$ and as salivary concentrations are $25 \%$ higher than serum concentrations, ${ }^{18}$ we defined non-smokers as those who reported being former smokers or who had never smoked and had salivary cotinine concentration $<113.6 \mathrm{nmol} / \mathrm{l}$ (20 $\mathrm{ng} / \mathrm{ml})$. We excluded people who claimed to be non-smokers but had salivary cotinine concentration $\geq 113.6 \mathrm{nmol} / \mathrm{l}$ as we considered them to be active smokers.

To measure any changes, we analysed symptoms individually, grouped into two dichotomous variables (any respiratory symptoms and any sensory symptoms), and as two symptom scores (total number of respiratory symptoms and total number of sensory symptoms reported by each individual).

Analyses (changes within pairs) were restricted to participants who took part in both baseline and follow-up surveys, who were still working in a pub, and who did not change their smoking status between baseline and follow-up. In before and after comparisons, differences between groups in characteristics that did not change, such as age and length of time in the bar trade (all increase by one year) and sex, are controlled internally. Univariate and bivariate analyses were conducted with JMP 5.0.1 (SAS Institute, Pacific Grove, CA), SPSS 12.0.1 (SPSS, Chicago, IL) and Mathematica 5.2 (Wolfram Research, Champaign, IL). As the data were skewed, we have presented medians and interquartile ranges for continuous data. We compared paired differences
Table 1 Participants in baseline and follow-up surveys of bar staff before and after smoking ban

\begin{tabular}{ccc} 
& Republic of Ireland & Northern Ireland \\
\hline Enrolled in baseline survey & $288(207$ from 140 pubs and & 41 (41 from 24 pubs) \\
& 81 from Mandate $\left.{ }^{\star}\right)$ & \\
\hline
\end{tabular}

Not eligible for follow-up:

\begin{tabular}{lcl}
\hline Total & 40 & 8 \\
\hline No longer in bar trade & 36 & 4 \\
\hline Moved & 3 & 4 \\
\hline Died & 1 & 0 \\
\hline Not followed up: & &
\end{tabular}

\begin{tabular}{lll}
\hline Not followed up: & \\
\hline Total & 28 & 4
\end{tabular}

\begin{tabular}{lcl}
\hline Total & 28 & 4 \\
\hline Not contactable & 19 & 4 \\
\hline Refused & 9 & 0
\end{tabular}

\begin{tabular}{ccc} 
Refused & 9 & 0 \\
\hline Follow-up rate & $76 \%(220 / 288)$ & $71 \%(29 / 41)$
\end{tabular}

\begin{tabular}{lll} 
Follow-up rate & $76 \%(220 / 288)$ & $71 \%(29 / 41)$ \\
\hline Follow-up rate in those eligible & $89 \%(220 / 248)$ & $88 \%(29 / 33)$
\end{tabular}
for follow-up

Cotinine concentrations

Available at baseline and

follow-up

Not availablet:

\begin{tabular}{lll}
\hline Total & 59 & 0 \\
\hline Insufficient & 20 & 0 \\
\hline Contaminated & 11 & 0 \\
\hline Refused & 28 & 0
\end{tabular}

Refused

Non-smokers

\begin{tabular}{lll}
\hline At baseline and follow-up & 138 & 20 \\
\hline With cotinine concentrations at & 111 & 20
\end{tabular}

With cotinine concentrations at

both surveys

*Mandate is the main trade union for Dublin bar workers.

t8 participants had no cotinine value at baseline, 21 had no cotinine value at follow-up, and 15 had no cotinine at either time.

using Wilcoxon signed rank test or McNemar's $\chi^{2}$ test for bivariate analyses and non-paired differences using Wilcoxon rank sum test, Pearson $\chi^{2}$, or Fisher's exact test.

The requirement to compare the Republic with Northern Ireland while simultaneously testing outcomes (continuoussuch as cotinine- or count-such as number of symptoms) at follow-up versus at baseline, together with the inclusion of both time varying covariates (such as hours worked in the past two days) and time constant covariates (such as sex), limits modelling possibilities to specific forms of generalised estimation equations. ${ }^{19}$ We used versions of generalised estimation equations for multiple regression (for changes per person in cotinine before and after the ban) and for Poisson regression (rate ratio for changes per person in the reported numbers of symptoms before and after the ban) using Stata 9 (StataCorp, College Station, TX). All covariates were tested in the models, but we retained only those that proved significant, plus age and sex. Interaction terms between region and time period were always fitted and retained in the model if the associated $\mathrm{P}$ value was less than 0.10 .

\section{Results}

We enrolled 329 bar staff at baseline and 249 in the follow-up survey (table 1). Forty eight were not eligible for follow-up, 23 could not be contacted after several attempts, and nine refused, giving a follow-up rate of $89 \%$ of those eligible or $76 \%$ overall in the Republic, and 88\% and 71\% in Northern Ireland. In total 226 participants in the baseline survey and 213 in the follow-up survey provided analysable saliva samples; 205 provided analysable samples in both surveys.

Most participants $(161 / 249,65 \%$ at baseline) were nonsmokers. We restricted analyses to the 158 who were still 
Table 2 Baseline characteristics of non-smoking* bar staff enrolled in both baseline and follow-up surveys. Values are medians (interquartile ranges) unless stated otherwise

\begin{tabular}{lccc} 
& $\begin{array}{c}\text { Republic of Ireland } \\
(\mathbf{n = 1 3 8})\end{array}$ & $\begin{array}{c}\text { Northern Ireland } \\
(\mathbf{n}=\mathbf{2 0})\end{array}$ & P value \\
\hline Age (years) & $45.5(35.0-54.9)$ & $36.1(20.9-43.8)$ & $<0.001$ \\
\hline No (\%) of women & $23(17)$ & $5(25)$ & 0.36 \\
\hline $\begin{array}{l}\text { Time working in current bar } \\
\text { (years) }\end{array}$ & $9(4-22)$ & $2(1.0-9.5)$ & 0.002 \\
$\begin{array}{l}\text { Hours worked/ week in current } \\
\text { job }\end{array}$ & $40(39.0-50.0)$ & $40(21.0-58.8)$ & 0.46 \\
$\begin{array}{l}\text { No (\%) with history of asthma } \\
\text { diagnosed by physician }\end{array}$ & $15(11)$ & $1(5)$ & 0.70 \\
\hline $\begin{array}{l}\text { No (\%) currently receiving } \\
\text { asthma prescription }\end{array}$ & $9(7.9)$ & 0 & 0.35 \\
\hline
\end{tabular}

*Non-smoker defined as participants who said they did not smoke or had given up and had salivary cotinine concentrations $<113.6 \mathrm{nmol} / \mathrm{l}$. Excludes participants who changed smoking status between surveys.

tP value for comparison of medians (Wilcoxon rank sum test) and categorical variables (Pearson $\chi^{2}$ or Fisher's exact test) at baseline and follow-up.

non-smokers at follow-up. Most participants were men. Participants from the Republic were older and had been working in the current pub for longer (table 2).

Those not followed up $(n=80)$ were significantly younger and more likely to be women, to smoke, to have worked for a shorter time in the current bar, and to have said they had asthma diagnosed by a physician than those followed up (data not shown).

Salivary cotinine concentrations declined significantly in both regions, but with a much greater decline in the Republic ( $80 \%$ v $20 \%$ in Northern Ireland). Cotinine concentrations for almost all the non-smokers in the Republic (106/111) fell compared with 14 out of 20 in Northern Ireland.

Self reported exposure to secondhand smoke was high before the ban, with smoke at work accounting for by far the greatest exposure (table 3). Work related exposure dropped to a far greater extent in the Republic (median of $40 v 0$ hours in the past week, $\mathrm{P}<0.001$ ) than in Northern Ireland (median $42 v 40$ hours, $\mathrm{P}=0.02)$. Exposures outside work also dropped significantly in the Republic (median $4 v 0$ hours, $\mathrm{P}<0.001$ ) but increased in Northern Ireland ( $0 v 2.5$ hours, $\mathrm{P}=0.41)$.

At baseline $65 \%$ of non-smokers in the Republic reported one or more respiratory symptom (table 4). This dropped by $25 \%$ to $49 \%(\mathrm{P}=0.001)$ at follow-up. After the ban, significantly fewer reported cough during the day or night $(\mathrm{P}=0.004)$ or production of phlegm $(\mathrm{P}=0.002)$. Similarly, after the ban, reporting any sensory symptom dropped from $67 \%$ to $45 \%(\mathrm{P}<0.001)$, reflecting significant declines in reporting red eyes $(\mathrm{P}<0.001)$ and sore throat $(\mathrm{P}=0.004)$. In Northern Ireland, the proportion reporting any respiratory symptom was lower at baseline (45\%) than in the Republic and remained at $45 \%$ after the ban, although reporting any sensory symptom declined from $75 \%$ to $55 \%(\mathrm{P}=0.13)$.

We modelled changes in cotinine concentrations and in the number of respiratory and sensory symptoms (table 5). After adjustment for relevant covariates, cotinine concentrations in non-smokers in the Republic dropped by $71 \%$ (from 35.8 to 10.2 $\mathrm{nmol} / \mathrm{l})$, more than twice as much as in Northern Ireland (34\% from 35.2 to $23.3 \mathrm{nmol} / \mathrm{l}$ ) (table 6 ).

Table 6 also shows that the adjusted rate ratio for the number of respiratory symptoms (symptoms at follow-up relative to symptoms at baseline) in the Republic dropped (from 1.33 to 0.98 ), while in Northern Ireland it increased by $16 \%$ (from 0.67 to 0.83 ). The adjusted rate ratio for the number of sensory symp-
Table 3 Exposure to secondhand smoke in non-smokers ${ }^{*}$ at baseline and follow-up surveys in the Republic of Ireland $(n=138)$ and Northern Ireland $(n=20)$. Values are medians (interquartile ranges) unless stated otherwise

\begin{tabular}{|c|c|c|c|c|}
\hline & Baseline & Follow-up & $\begin{array}{c}P \\
\text { value }\end{array}$ & $\begin{array}{l}\text { Difference }(95 \% \\
\text { CI) } \ddagger\end{array}$ \\
\hline \multicolumn{5}{|l|}{ Republic of Ireland } \\
\hline \multicolumn{5}{|l|}{ Secondhand smoke exposure: } \\
\hline Salivary cotinine $(\mathrm{nmol} / \mathrm{l}) \S$ & $\begin{array}{c}29.0 \\
(18.2-43.2)\end{array}$ & $\begin{array}{c}5.1 \\
(2.8-13.1)\end{array}$ & $<0.001$ & $\begin{array}{c}-22.7 \\
(-26.7 \text { to }-19)\end{array}$ \\
\hline \multicolumn{5}{|l|}{ Self reported exposure: } \\
\hline $\begin{array}{l}\text { Hours exposed at work (pub } \\
\text { or bar) during past } 7 \text { days }\end{array}$ & $40(39-50)$ & 0 & $<0.001$ & $\begin{array}{c}-40 \\
(-47 \text { to }-41.5)\end{array}$ \\
\hline $\begin{array}{l}\text { Hours exposed outside work } \\
\text { (domestic or social) during } \\
\text { past } 7 \text { days }\end{array}$ & $4(0-10)$ & $0(0-2)$ & $<0.001$ & $\begin{array}{c}-1.25 \\
(-4 \text { to }-1.5)\end{array}$ \\
\hline No (\%) living with smoker & 37 (26.8) & $36(26.1)$ & 0.79 & $\begin{array}{c}-0.7 \\
(-6.9 \text { to } 5.5)\end{array}$ \\
\hline Hours worked in past 2 days & $13(9-19.5)$ & $13(7.1-18)$ & 0.01 & $-2(-3$ to -0.5$)$ \\
\hline \multicolumn{5}{|l|}{ Northern Ireland } \\
\hline \multicolumn{5}{|l|}{ Secondhand smoke exposure: } \\
\hline Salivary cotinine $(\mathrm{nmol} / \mathrm{l}) \S$ & $\begin{array}{c}25.3 \\
(10.4-59.2)\end{array}$ & $\begin{array}{c}20.4 \\
(13.2-33.8) \\
\end{array}$ & 0.05 & $\begin{array}{c}-5.7 \\
(-21.3 \text { to }-3.7) \\
\end{array}$ \\
\hline \multicolumn{5}{|l|}{ Self reported exposure: } \\
\hline $\begin{array}{l}\text { Hours exposed at work (pub } \\
\text { or bar) during past } 7 \text { days }\end{array}$ & $42(15-55)$ & $40(6.5-45)$ & 0.02 & $\begin{array}{c}-3 \\
(-11.5 \text { to }-0.5)\end{array}$ \\
\hline $\begin{array}{l}\text { Hours exposed outside work } \\
\text { (domestic or social) during } \\
\text { past } 7 \text { days }\end{array}$ & $0(0-10)$ & $2.5(0-18)$ & 0.41 & $0(-2.5$ to 7.5$)$ \\
\hline No (\%) living with smoker & $6(30)$ & $6(31.6)$ & 1.00 & 0 (-19.9 to 19.9$)$ \\
\hline Hours worked in past 2 days & $12(0-19)$ & $10(4-14)$ & 0.63 & -1.25 ( -6 to 3.3$)$ \\
\hline
\end{tabular}

\section{IQR=interquartile range}

${ }^{\star}$ Non-smokers defined as participants who said they did not smoke or had given up and had salivary cotinine concentrations $<113.6 \mathrm{nmol} / \mathrm{l}$ at both baseline and follow-up surveys. Excludes participants who changed smoking status between surveys.

$\dagger P$ value for comparison of medians (Wilcoxon signed rank test) and categorical variables (McNemar $\chi^{2}$ test) at baseline and follow-up.

$\ddagger$ Differences refer either to medians or percentages

$\S$ Values are for 131 participants (111 in the Republic of Ireland and 20 in Northern Ireland) with cotinine concentrations at both baseline and follow-up survey.

toms dropped substantially in both regions (by 50\% in the Republic and by $44 \%$ in Northern Ireland).

\section{Discussion}

\section{Main findings}

This study shows that the smoking ban in the Republic of Ireland has led to a clear reduction in self reported exposure to secondhand smoke in and outside work. In non-smokers, salivary cotinine concentrations dropped by $80 \%$ and respiratory and sensory symptoms were significantly fewer. Smaller reductions were observed in Northern Ireland. The adjusted reduction in cotinine concentration was twice as great in the Republic as in Northern Ireland and respiratory symptoms also declined to a significantly greater extent.

It has been suggested that banning smoking in pubs and restaurants would lead to increased smoking in the home. ${ }^{20}$ Although we did not ask specifically about exposure at home, our data do not support this contention as self reported exposure to secondhand smoke outside work dropped significantly in the Republic, but increased in Northern Ireland (table 3).

The unexpected improvements in Northern Ireland may be explained by a decline in the pub trade. At follow-up, participants from Northern Ireland reported working fewer hours in the past two days (12 hours $v 10$, table 3). An economic downturn in the north west region, ${ }^{21}$ avoidance of drink driving, and stricter enforcement of regulations on underage drinking may be contributory factors. Some of the same factors may also 
Table 4 Respiratory and sensory irritation symptoms at baseline and at follow-up surveys among non-smokers* in the Republic of Ireland and Northern Ireland ( $\mathrm{n}=138$ and 20 ). Values are numbers (percentages) unless stated otherwise

\begin{tabular}{|c|c|c|c|c|}
\hline & \multicolumn{2}{|c|}{ No (\%) with symptoms } & \multirow[b]{2}{*}{$\mathrm{P}$ value $\dagger$} & \multirow[b]{2}{*}{ Difference $(95 \% \mathrm{CI}) \neq$} \\
\hline & Baseline & Follow-up & & \\
\hline \multicolumn{5}{|l|}{ Republic of Ireland } \\
\hline \multicolumn{5}{|l|}{ Respiratory symptoms: } \\
\hline $\begin{array}{l}\text { Median (IQR) No of } \\
\text { symptoms }\end{array}$ & $1(0-2)$ & $0(0-2)$ & 0.001 & $0(-0.5$ to 0$)$ \\
\hline Any symptom & $90(65)$ & $67(49)$ & 0.001 & $-16.7(-26.1$ to -7.3$)$ \\
\hline Wheezing/whistling & $29(21)$ & $27(20)$ & 0.86 & $-1.5(-9.9$ to 7.1$)$ \\
\hline Shortness of breath & $22(16)$ & $22(16)$ & 1.00 & 0 (-8.2 to 8.2$)$ \\
\hline Cough, morning & $29(21)$ & $20(15)$ & 0.14 & $-6.5(-14.8$ to 1.8$)$ \\
\hline Cough, rest of day or night & $53(38)$ & $34(25)$ & 0.004 & $-13.8(-23.1$ to -4.5$)$ \\
\hline Phlegm production & $59(43) \S$ & $40(29)$ & 0.002 & $-14.7(-24.0$ to -5.4$)$ \\
\hline \multicolumn{5}{|l|}{ Sensory symptoms: } \\
\hline $\begin{array}{l}\text { Median (IQR) No of } \\
\text { symptoms }\end{array}$ & $1(0-2)$ & $0(0-1)$ & $<0.001$ & $-1(-1.27$ to -0.7$)$ \\
\hline Any symptom & $93(67)$ & $62(45)$ & $<0.001$ & $\begin{array}{c}-22.5 \\
(-33.8 \text { to }-11.1)\end{array}$ \\
\hline Eyes, red or irritated & $57(41)$ & $19(14)$ & $<0.001$ & $\begin{array}{c}-27.5 \\
(-37.4 \text { to }-17.7) \\
\end{array}$ \\
\hline Nose, runny or sneezing & $61(44)$ & $48(35)$ & 0.08 & $-9.4(-19.8$ to 0.9$)$ \\
\hline Throat, sore or scratchy & $46(33)$ & $26(19)$ & 0.004 & $-14.5(-24.3$ to -4.7$)$ \\
\hline \multicolumn{5}{|l|}{ Northern Ireland } \\
\hline \multicolumn{5}{|l|}{ Respiratory symptoms: } \\
\hline $\begin{array}{l}\text { Median (IQR) No of } \\
\text { symptoms }\end{array}$ & $0(0-1)$ & $0(0-1)$ & 0.53 & $0(-0.5$ to 1$)$ \\
\hline Any symptom & $9(45)$ & $9(45)$ & 1.00 & $0(-32.7$ to 32.7$)$ \\
\hline Wheezing/whistling & $1(5)$ & $1(5)$ & 1.00 & $0(-18.9$ to 18.9$)$ \\
\hline Shortness of breath & $5(25)$ & $3(15)$ & 0.69 & -10 (-38.6 to 18.6$)$ \\
\hline Cough, morning & $1(5)$ & $3(15)$ & 0.50 & 10.0 (-8.1 to 28.1) \\
\hline Cough, rest of day or night & $2(10)$ & $3(15)$ & 1.00 & $5.0(-16.8$ to 26.8$)$ \\
\hline Phlegm production & $4(20)$ & $6(30)$ & 0.63 & $10.0(-14.1$ to 34.1$)$ \\
\hline \multicolumn{5}{|l|}{ Sensory symptoms: } \\
\hline $\begin{array}{l}\text { Median (IQR) No of } \\
\text { symptoms }\end{array}$ & $1(0.3-2)$ & $1(0-1)$ & 0.07 & $0(-1$ to 0.5$)$ \\
\hline Any symptom & $15(75)$ & $11(55)$ & 0.13 & -20.0 (-42.5 to 2.5$)$ \\
\hline Eyes, red or irritated & $9(45)$ & $8(40)$ & 1.00 & $-5.0(-31.8$ to 21.8$)$ \\
\hline Nose, runny or sneezing & $10(50)$ & $5(25)$ & 0.06 & $-25(-49.0$ to -1$)$ \\
\hline Throat, sore or scratchy & $4(20)$ & $3(15)$ & 1.00 & $-5.0(-35.8$ to 25.8$)$ \\
\hline
\end{tabular}

\section{$\mathrm{IQR}=$ interquartile range.}

${ }^{*}$ Non-smokers defined as participants who said they did not smoke or had given up and had salivary cotinine concentrations $<113.6 \mathrm{nmol} / \mathrm{l}$ at baseline and follow-up surveys. Excludes participants who changed smoking status between surveys.

$\dagger P$ value for McNemar $\chi^{2}$ test for paired comparison of individual symptoms and Wilcoxon signed rank test for comparing median number of symptoms at baseline and follow-up.

tDifferences refer either to medians or percentages.

§Two respondents did not answer this question.

be operating in the Republic alongside the high cost of drinking in pubs and a $9 \mathrm{pm}$ watershed for people aged under 18 , all contributing to a downturn in the pub trade.

\section{Comparison with other studies}

There have been few follow-up studies of bar workers. The San Francisco study was small, based in a single city, and did not include biomarkers for assessment of secondhand smoke. ${ }^{13}$ Follow-up studies in New York $^{22}$ and Norway ${ }^{23}$ were not focused (exclusively) on bar staff and had low follow-up rates. None included a control population.

As in the San Francisco study ${ }^{13}$ we found dramatic decreases in self reported exposure to secondhand smoke at work and reductions in respiratory and sensory symptoms. The reductions in salivary cotinine concentrations in non-smoking hospitality workers in New York $^{22}$ were of a similar magnitude to those in our study. They reported significant reductions in the numbers of sensory symptoms but not of respiratory symptoms.
Table 5 Modelled changes in non-smokers. Figures are regression coefficients (95\% confidence intervals) for cotinine concentrations and rate ratios (95\% confidence intervals) for respiratory and sensory symptoms

\begin{tabular}{|c|c|c|}
\hline & $\begin{array}{l}\text { Regression coefficient or } \\
\text { rate ratio }(95 \% \mathrm{CI})\end{array}$ & $P$ value \\
\hline \multicolumn{3}{|l|}{ Cotinine concentrations (nmol/l) $(\mathrm{n}=131)$} \\
\hline Region (Republic:Northern Ireland) & $0.022(-1.56$ to 1.61$)$ & 0.978 \\
\hline Time period (follow-up:baseline) & $-1.99(-3.64$ to -0.36$)$ & 0.017 \\
\hline Live with smoker (yes:no) & 1.62 (0.62 to 2.62$)$ & 0.002 \\
\hline Hours worked in past 2 days & 0.07 (0.01 to 0.13$)$ & 0.011 \\
\hline Age (years) & $-0.03(-0.07$ to 0.001$)$ & 0.053 \\
\hline Sex (female:male) & $0.94(-0.28$ to 2.16$)$ & 0.134 \\
\hline Interaction between region and time period & $-2.40(-4.18$ to -0.62$)$ & 0.008 \\
\hline Constant & 6.19 (4.25 to 8.12$)$ & $<0.001$ \\
\hline \multicolumn{3}{|l|}{ Respiratory symptoms ( $\mathrm{n}=158$ ) } \\
\hline Region (Republic:Northern Ireland) & 1.96 (1.11 to 3.48$)$ & 0.021 \\
\hline Time period (follow-up:baseline) & 1.22 (0.72 to 2.08$)$ & 0.447 \\
\hline Age (years) & 1.00 (0.99 to 1.01$)$ & 0.487 \\
\hline Sex (female: male) & 0.44 (0.28 to 0.69$)$ & $<0.001$ \\
\hline Interaction between region and time period & $0.60(0.35$ to 1.04$)$ & 0.070 \\
\hline \multicolumn{3}{|l|}{ Sensory symptoms $(\mathrm{n}=158)$} \\
\hline Region (Republic:Northern Ireland) & $1.14(0.77$ to 1.70$)$ & 0.507 \\
\hline Time period (follow-up:baseline) & 0.57 (0.47 to 0.71$)$ & $<0.001$ \\
\hline Age (years) & 0.99 (0.98 to 1.00$)$ & 0.063 \\
\hline Sex (female:male) & 0.86 (0.60 to 1.22$)$ & 0.398 \\
\hline Hours worked in past week & $0.99(0.98$ to 1.00$)$ & 0.089 \\
\hline
\end{tabular}

Preliminary results from Norway show significant reductions in both respiratory and sensory symptoms. ${ }^{23}$

\section{Strengths of study}

We managed to enrol a large number of bar staff and our follow-up rate was high. The study evaluated a national law, bar staff were enrolled from three differing areas, and the inclusion of Northern Ireland allowed us to control for secular trends unrelated to the legislative change and hence estimate how much of the change was due to the new law.

In bodily fluids, cotinine, with a half life of around 20 hours, ${ }^{16}$ is a good indicator of exposure to smoke over the previous two to three days. We used a combination of cotinine and self reported exposure as this is considered the best way of estimating exposure. ${ }^{24}$

The substantial declines in personal exposure of bar staff reported here are corroborated by measurements of particulate concentrations in pubs. Significant reductions (typically $60-80 \%$ ) were observed after the introduction of the workplace smoking

Table 6 Modelled estimates (95\% confidence intervals) for time period within region

\begin{tabular}{llc} 
& \multicolumn{1}{c}{ Baseline } & Follow-up \\
\hline Cotinine concentration* & & \\
\hline Republic of Ireland & $35.8(31.8$ to 39.2$)$ & 10.2 (6.8 to 13.6$)$ \\
\hline Northern Ireland & $35.2(27.3$ to 43.7$)$ & 23.3 (15.3 to 32.4$)$ \\
\hline Rate ratios for respiratory symptoms $\dagger$ & \\
\hline Republic of Ireland & $1.33(1.14$ to 1.54$)$ & $0.98(0.83$ to 1.16$)$ \\
\hline Northern Ireland & $0.67(0.39$ to 1.17$)$ & $0.83(0.50$ to 1.36$)$ \\
\hline Rate ratios for sensory symptoms $\neq$ & & \\
\hline Republic of Ireland & $1.19(1.02$ to 1.39$)$ & $0.69(0.57$ to 0.85$)$ \\
\hline Northern Ireland & $1.09(0.75$ to 1.56$)$ & $0.65(0.44$ to 0.97$)$ \\
\hline
\end{tabular}

${ }^{*}$ Adjusted for region, time period, living with smoker, hours worked in past 2 days, age, sex, interaction between region and time period, and constant, all set to average values.

†Adjusted for region, time period, age, sex, and interaction between region and time period all set to average values.

$\ddagger$ Adjusted for region, time period, age, sex, and hours worked in past week all set to average values. 


\section{What is already known on this topic}

Secondhand smoke has adverse effects on health, including respiratory health

Smoke-free policies are associated with decreased exposure in the hospitality sector and possibly a rapid improvement in respiratory health in bar workers, though the size of these effects relative to underlying trends is unknown

\section{What this study adds}

After the introduction of comprehensive smoke-free workplace legislation in the Republic of Ireland, exposure to secondhand smoke and respiratory symptoms declined in non-smoking bar staff

The reductions were significantly higher than the unanticipated reductions observed in the control region

ban in both Dublin (http://tri.ie/ResearchResults/tabid/61/ Default.aspx) and Galway pubs. ${ }^{25}$

\section{Limitations of study}

The lack of national or regional sampling frames precluded random sampling. The low take up at baseline, a feature of other studies in this setting, ${ }^{13}{ }^{22}$ reflects the pervasive anxiety in the trade at that time about the impending ban. Because we used volunteer sampling, the cotinine concentrations and frequencies of symptoms reported here may not be generalisable. By choosing different types of pub from urban and rural areas, however, we have provided an overall picture of the impact of the ban.

The small number not followed up differed from the overall group but this does not compromise study validity because of the paired design. Although the numbers enrolled from Northern Ireland were small, they were sufficient to detect significant changes.

\section{Recommendations for further research}

Although perceived health is important, objective testing of lung function and longer follow-up are required to assess the long term impact of the ban. Our results suggest that home exposure may have declined after the ban. Incorporation of testing of salivary cotinine concentrations in children into national longitudinal studies would be an objective way to monitor future exposures in countries considering the introduction of similar legislation. Secondhand exposure to smoke in exempted workplaces (such as prisons, psychiatric institutions, and hospices) should be monitored to assess the need for protection of their staff.

\section{Implications of findings}

The smoke-free workplace law in the Republic of Ireland has provided protection for one of the most heavily exposed occupational groups by reducing their exposure to secondhand smoke both in and out of the workplace. The reduced exposure has led to a decline in respiratory and sensory symptoms in nonsmokers. The increase in support for the law in the Republic since its introduction, even among smokers, underpins its effectiveness. ${ }^{26}$ These findings have implications for policy makers and legislators in other countries currently considering the nature and extent of their smoke-free workplace legislation.

We thank Mandate for their support, especially John Douglas and Sandra Browne; Sangeetha N Kalimuthu, Meenakshi Uppel, Katherine O'Mahony, Micheál Breen, Mairead McMahon, Michael Keogh, Maire Galvin, and
Damian Gavin for help with interviews; Paul Blanc and Mark Eisner for advice and for allowing us to use their questionnaire; Luke Clancy, Michele Agnew, and Pat Goodman for contributing to study design and planning, for the Dublin ethics committee protocol, and for use of respiratory laboratory premises at St James's Hospital; Alan Smith for comments on study design; Geoffrey Fong for his assistance and support; members of the Trinity College Department of Public Health and Primary Care for comments on a preliminary draft; and Ailbhe Mealy and Deirdre Handy for typing and editing assistance. We especially thank the bar staff and bar owners who participated in the interviews.

Contributors: All authors reviewed and approved the final version of this manuscript. SA conceptualised the study and was involved in and coordinated all aspects of the study, performed most of the analyses, wrote all drafts of the paper, and is guarantor. GP participated in design, preparation of study materials and protocol, data collection, data entry/editing, interpretation, and preparation of drafts. BG and LP participated in design, preparation of study materials and protocol, interpretation, and preparation of drafts. BJM participated in design, preparation of study materials and protocol, data collection, data entry/editing, and preparation of drafts. AK was statistical adviser, conducted statistical modelling, and participated in the interpretation. MD'E participated in data collection, data entry/editing, and commented on drafts. EO'K participated in design and data collection and commented on drafts of the manuscript. JPMcL participated in the research design and protocol preparation and commented on drafts. DO'D participated in the research design and protocol preparation, contributed to preparation of study materials, and commented on drafts. $\mathrm{BB}, \mathrm{BMcC}$, and IJP participated in design and commented on drafts.

Funding: Office of Tobacco Control through the Research Institute for a Tobacco Free Society (Republic of Ireland); the National Cancer Institute of the United States (R01 CA90955); Irish Cancer Society; Irish Heart Foundation; Health Service Executive, Western Area, and Western Investing for Health Partnership (Northern Ireland). Mandate Trade Union provided two prizes for a draw.

Competing interest: SA is a member of the Board of the Irish Office of Tobacco Control (unpaid position). IJP is chairman of the Irish Research Institute for a Tobacco Free Society.

Ethical approval: Research ethics committee of the Faculty of Public Health Medicine, Royal College of Physicians of Ireland; the St. James's Hospital and Federated Dublin Voluntary Hospitals joint research ethics committee; the clinical research ethics committee of the Cork Teaching Hospitals; and the healthcare committee and senior management team of the Western Health and Social Services Board and the Western Investing for Health Partnership.

1 International Agency for Research on Cancer Working Group on the Evaluation of Carcinogenic Risks to Humans. Tobacco smoke and involuntary smoking. Lyon: IARC Press, 2004.

2 California Environmental Protection Agency. Health effects of exposure to environmental tobacco smoke. Sacramento: California Environmental Protection Agency, National Cancer Institute, National Institutes of Health, 1997.

3 Allwright S, McLaughlin JP, Murphy D, Pratt I, Ryan M, Smith A. Report on the health effects of environmental tobacco smoke (ETS) in the workplace. Dublin: Health and Safety Authority/Office of Tobacco Control, 2003.

4 Howell F. Ireland's workplaces, going smoke free. BMJ 2004:328:847-8.

5 Allwright SPA. Republic of Ireland's indoor workplace smoking ban. Br J Gen Pract 2004;54:811-2.

6 Tobacco Advisory Group of the Royal College of Physicians. Going smoke-free. The medical case for clean air in the home, at work and in public places. London: Royal College of Physicians, 2005

7 Kawachi I. More evidence on the risks of passive smoking. BMJ 2005;330:265-6.

8 Heloma A, Jaakkola MS. Four-year follow-up of smoke exposure, attitudes and smoking behaviour following enactment of Finland's national smoke-free work-place law. Addiction 2003;98:1111-7.

9 European Network for Smoking Prevention. Smoke free workplaces: Improving the health and well-being of people at work. Brussels: European Network for Smoking Prevention (ENSP), 2001.

10 Jarvis MJ, Foulds J, Feyerabend C. Exposure to passive smoking among bar staff. Br J Addict 1992;87:111-3.

11 Bates MN, Fawcett J, Dickson S, Berezowski R, Garrett N. Exposure of hospitality workers to environmental tobacco smoke. Tob Control 2002;11:125-9.

12 Mulcahy M, Repace J. Passive smoking exposure and risk for Irish bar staff. In: Proceedings of indoor air 2002. 9th International Conference on Indoor Air Quality and Climate. Monterey, CA: Indoor Air, 2002:44.

13 Eisner MD, Smith AK, Blanc PD. Bartenders' respiratory health after establishment of smoke-free bars and taverns. JAMA 1998;280:1909-14.

14 Sproston K, Primatesta P. Health survey for England 2003. Vol 3. Methodology and documentation. London: Stationery Office, 2004.

15 Feyerabend C, Russell MAH. A rapid gas-liquid chromatographic method for the

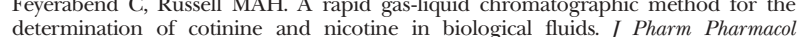
determination

16 Jacob III P, Yu L, Shulgin AT, Benowitz NL. Minor tobacco alkaloids as biomarkers for tobacco use: comparison of users of cigarettes, smokeless tobacco, cigars, and pipes. Am 
17 Pirkle JL, Flegal KM, Bernert JT, Brody DJ, Etzel RA, Maurer KR. Exposure of the US population to environmental tobacco smoke. The third health and nutrition examination survey, 1988 to 1991. JAMA 1996;275:1233-40.

18 Jarvis M, Primatesta P, Erens B, Feyerabend C, Bryant A. Measuring nicotine intake in population surveys: comparability of saliva cotinine and plasma cotinine estimates. Nicotine Tob Res 2003;5:349-55.

19 Liang K-Y, Zeger SL. Longitudinal data analysis using generalized linear models Biometrika 1986;73:13-22.

20 Hinchliffe D. The Government's public health white paper (Cm 6374): minutes of evidence. London: UK Parliament House of Commons Health Committee, 23 Feb 2005. www.parliament.the-stationery-office.co.uk/pa/cm200405/cmselect/cmhealth/358/ 5022301.htm (accessed 11 Oct 2005).

21 Tunney M. New rural enterprises can reverse job losses. Irish Times 2005 August 24.

22 Farrelly MC, Nonnemaker JM, Chou R, Hyland A, Peterson KK, Bauer UE. Changes in hospitality workers' exposure to secondhand smoke following the implementation of New York's smoke-free law. Tob Control 2005;14:236-41.

23 Lund J, Lund M, Rise J, Aaro LE, Hetland J. Smoke-free bars and restaurants in Norway. Olso: HEMIL/SIRUS, 2005

24 Chen R, Tavendale R, Tunstall-Pedoe H. Measurement of passive smoking in adults: self reported questionnaire or serum cotinine? J Cancer Epidemiol Preun 2002;7:85-95.

25 Mulcahy M, Byrne MA, Ruprecht A. How does the Irish smoking ban measure up? A before and after study of particle concentrations in Irish pubs. Indoor Air 2005;15(suppl 11):86.

26 Fong GT, Hyland A, Borland R, Hammond D, Hastings G, McNeill A, et al. Reduction in tobacco smoke pollution and increases in support for smoke-free public places following the implementation of comprehensive smoke-free workplace legislation in the Republic of Ireland: findings from the ITC Ireland/UK survey. Tob Control (in press).

(Accepted 7 October 2005)

doi $10.1136 /$ bmj.38636.499225.55
Department of Public Health and Primary Care, University of Dublin, Trinity College, Trinity College Centre for Health Sciences, AMNCH, Tallaght, Dublin 24, Republic of Ireland

Shane Allwright senior lecturer in epidemiology

Gillian Paul research fellow

Alan Kelly senior lecturer in biostatistics

Department of Epidemiology and Public Health, University College Cork,

Brookfield Health Sciences Complex, Cork, Republic of Ireland

Birgit Greiner senior lecturer in epidemiology and public health

Bernie J Mullally research associate

Ivan J Perry professor of public health

Department of Health Promotion, National University of Ireland, Galway, Republic of Ireland

Lisa Pursell senior researcher

Maureen D'Eath researcher

Diarmuid O'Donovan senior lecturer in social and preventive medicine

Western Investing for Health Partnership, Londonderry BT47 6FN, Northern

Ireland

Brendan Bonner manager

Department of Public Health Medicine, Western Health and Social Services Board, Londonderry BT47 6FN

Bill McConnell director

School of Physics, University College Dublin, Belfield, Dublin 4

James P McLaughlin senior lecturer in physics

Derry Healthy Cities, The Old Nursing Home, Altnagelvin Hospital, Londonderry BT47 6SB

Eamon O'Kane director

Correspondence to: S Allwright sllwrght@tcd.ie 